\title{
Renewable Technology Adoption and the Macroeconomy*
}

\author{
Bernardino Adao \\ Bank of Portugal
}

\author{
Borghan Narajabad \\ Rice University
}

Ted Temzelides

Rice University

First Version: 1/25/2012

\begin{abstract}
We study the adaptation of new technologies by renewable energy-producing firms in a dynamic general equilibrium model where energy is an input in the production of goods. Energy can come from fossil or renewable sources. Both require the use of capital, which is also needed in the production of final goods. Renewable energy firms can invest in improving the productivity of their capital stock. The actual improvement is subject to spillovers and comes at the cost of some renewable energy output. Together with spill-overs, this leads to under-investment in improving the productivity of renewable energy capital. In the presence of environmental externalities, the optimal allocation can be implemented through a Pigouvian tax on fossil fuel, together with a policy which promotes adaptation of new renewable technologies. We study numerical examples using world-economy data.
\end{abstract}

${ }^{*}$ We are grateful to many colleagues, especially Peter Hartley and Antonia Diaz, for discussions and comments. We also thank participants at the Yale University Cowles Foundation Summer Conference on "Macroeconomics and Climate Change," the Qatar Petroleum Workshop in Doha, Qatar, the Vienna Macro Conference, the CESifo conference on Energy and Climate Economics, SMU, and the ASSA Meetings for their comments. 


\section{Introduction}

Economic growth generates a tremendous demand for energy. Historically, this need has been met largely through the use of fossil fuel. In recent decades, renewable energy sources (such as solar and wind) have been increasing their representation in many nations' energy supply. As concerns about the consequences of climate change become more prevalent, and as fossil fuel inevitably becomes more scarce, it is likely that renewable energy will become even more widely used. While renewable energy is still too costly to directly compete with fossil fuel sources in many areas, the transition towards renewable energy supplies is expected to accelerate as investment in this sector increases, and as the resulting technological progress reduces costs.

A widely held view holds that societies currently under-invest in renewable energy. This argument can take many different forms. Under-investment might refer to resources spent on $\mathrm{R} \& \mathrm{D}$, or on actual installation and usage of facilities that harvest renewable energy. Similarly, the reasons for under-investment range from externalities associated with climate change, to spillovers associated with innovation. In order to evaluate alternative policies, we need to have an idea about the rate at which declining costs will lead to increased competitiveness for renewables. What determines the productivity improvements in renewable energy production? How does the rate of productivity improvement respond to policy? What are the consequences for the fossil fuel sector and the macroeconomy? Our paper attempts to study these questions in the context of a structural dynamic general equilibrium model.

We investigate the full transition from a mainly fossil-fuelled to a mainly renewable energy-fueled world economy. This transition involves several different aspects. First, although fossil fuel sources are plentiful, they constitute an exhaustible resource. Increasing scarcity rents resulting from accumulated use, lead to an increased demand for a substitute. A second important ingredient involves environmental considerations. We follow Golosov, Hassler, Krusell, and Tsyvinski (2011) in the way we model this externality. As fossil fuel generates externalities due to carbon emissions, the need for a clean substitute becomes more prevalent. Lastly, we model the process of innovation in the renewable energy sector. This process has two important ingredients. First, spillovers imply that investment in the renewable technology has both a direct and an indirect effect. Second, investing in new technologies results in some loss in the current production of renewable energy.

We develop a model where energy is an input in the production of a consumption good. Energy can be produced from either fossil or renewable sources. Both require capital, which is also needed for the production of the final good. At each point in time, renewable energyproducing firms can improve their productivity. The actual improvement is subject to a spillover: it depends on the aggregate investment in the renewable sector. The spill-over effect leads to an overall under-investment in renewable energy. The optimal mix of energy supply involves a declining use of fossil fuel. We demonstrate that the optimal allocation can be implemented through a policy which promotes renewables, together with a Pigouvian tax on the environmental externality created by fossil fuel use. In equilibrium, the policies promoting renewables are revenue-neutral. We calibrate the model using world-economy 
data and study the implications of various proposed tax/subsidy scenarios for economic growth.

While our analysis concentrates on the energy sector, our modeling of productivity improvements might have applications in other areas. Parente (1994) studies a model in which firms choose to adopt new technologies as they gain firm-specific expertise through learningby-doing. He identifies conditions under which equilibria in his model exhibit constant growth of per capita output. As in most of the literature on economic growth, Parente abstracts from issues related to energy. Acemoglu et al (2012) study a growth model that takes into consideration the environmental impact of operating "dirty" technologies. They examine the effects of policies that tax innovation and production in the dirty sectors. They find that subsidizing research in the "clean" sectors can speed up environmentally friendly innovation without the corresponding slowdown in economic growth. Consequently, optimal behavior in their model implies an immediate increase in clean energy R\&D, followed by a complete switch toward the exclusive use of clean inputs in production. Manuelli and Seshadri study technology diffusion of tractors in American agriculture during the first part of the twentieth century and argue that part of the reason for the slow rate of diffusion was that tractor quality kept improving over this period.

More recently, Golosov, Hassler, Krusell, and Tsyvinski (GHKT, 2011) built a macroeconomic model that incorporates the use of energy and the resulting environmental consequences. They derive a formula describing the optimal tax due to the externality from emissions and provide numerical values for the size of the tax in a calibrated version of their model. However, they abstract from the costs associated with endogenous technological progress, which are the focus of our study. Acemoglu, D., U. Akcigit, D. Hanley, and W. Kerr (2012), use the structure in GHKT, 2011 to study questions related to the transition to clean technologies. They employ a "ladder" model to study technological progress in both the clean and the dirty sectors, and they estimate the model using R\&D and patent data. They find that, in addition to carbon taxes, quantitatively significant R\&D subsidies are a necessary ingredient of optimal policy. The reason is that subsidies encourage technological progress without over-taxing short run future output. ${ }^{1}$

The paper proceeds as follows. The next section introduces the economic environment and discusses efficiency. Section 3 studies equilibrium allocations and optimal policy. Section 4 introduces our calibration and policy scenarios. A brief conclusion follows.

\section{The Economic Environment}

We assume discrete time and infinite horizon, $t=0,1, \ldots$ There is a single consumption good per period and all markets are competitive. The economy is populated by a representative infinite-lived household. The household discounts the future at rate $\beta \in(0,1)$ and values the period- $t$ consumption good through a utility function $u\left(c_{t}\right)$. We assume that $u$ is smooth,

\footnotetext{
${ }^{1}$ Other related papers include Hartley, Medlock, Temzelides, and Zhang (2012) and Van der Ploeg F., and C. Withagen (2011), who study the possibility of a Green Paradox.
} 
strictly increasing, strictly concave, and that the usual Inada conditions hold. There are three different kinds of firms, all owned by the household. In each period, the household chooses how much capital, $k$, to rent in the market at rate $r$, and receives all profits resulting from firms' activities. All capital depreciates at the same rate, $\delta \in(0,1)$.

The final-good producing firm uses capital, $k$, labor, $L$, and energy, $e$, in order to produce output. The labor endowment is normalized to 1 , and is supplied inelastically to the firm. In addition, we assume that environmental quality, $\Gamma$, can affect the production process through a damage function $D(\Gamma)$. The final good production function is given by

$$
\begin{aligned}
y_{t} & \leq A_{t}\left(k_{t}^{g}\right)^{\theta_{k}}\left(L_{t}\right)^{\theta_{L}}\left(e_{t}\right)^{1-\theta}=\left(1-D_{t}\left(\Gamma_{t}\right)\right)\left[\widetilde{A}_{t}\left(k_{t}^{g}\right)^{\theta_{k}}\left(L_{t}\right)^{\theta_{L}}\left(e_{t}\right)^{1-\theta}\right] \\
& =\exp \left[-\pi_{t}\left(\Gamma_{t}-\bar{\Gamma}\right)\right] \widetilde{A}_{t}\left[\left(k_{t}^{g}\right)^{\theta_{k}}\left(L_{t}\right)^{\theta_{L}}\left(e_{t}\right)^{1-\theta}\right]
\end{aligned}
$$

where $\widetilde{A}$ is a productivity parameter, $A_{t}=\left(1-D_{t}(\Gamma)\right) \widetilde{A}_{t}$, and $\theta, \theta_{k}, \theta_{L} \in(0,1)$, and $\theta_{k}+\theta_{L}=$ $\theta$. Following Golosov, Hassler, Krusell, and Tsyvinski (GHKT, 2011), we assume that

$$
D_{t}(\Gamma)=1-\exp \left[-\pi_{t}\left(\Gamma_{t}-\bar{\Gamma}\right)\right]
$$

where $\bar{\Gamma}$ is the pre-industrial greenhouse gas concentration in the atmosphere, and $\pi$ is a random variable which parametrizes the effect of higher greenhouse gas concentrations on the level of damages. Environmental quality evolves according to

$$
\Gamma_{t}=\sum_{l=0}^{t+T}\left(1-d_{l}\right) f_{t-l}
$$

where $d_{l} \in[0,1]$, and $f_{l}$ is the fossil fuel use in period $l$. Assuming that a fraction $\varphi_{L}$ of emitted carbon stays in the atmosphere for ever, while a fraction $\left(1-\varphi_{0}\right)$ of the remaining emissions exits into the biosphere, and the remaining part decays at geometric rate $\varphi$, we obtain

$$
\begin{aligned}
1-d_{l} & =\varphi_{L}+\left(1-\varphi_{L}\right) \varphi_{0}(1-\varphi)^{l} \\
\Gamma_{t}^{p} & =\Gamma_{t-1}^{p}+\varphi_{L} f_{t} \\
\Gamma_{t}^{d} & =(1-\varphi) \Gamma_{t-1}^{d}+\left(1-\varphi_{L}\right) \varphi_{0} f_{t} \\
\Gamma_{t} & =\Gamma_{t}^{p}+\Gamma_{t}^{d}
\end{aligned}
$$

Energy can be produced in two different ways by using a fossil or a renewable source. We assume that the two types of energy are perfect substitutes in the production of the final good. ${ }^{2}$ We let $w_{t}$ denote the available stock of fossil fuel in period $t$, while, as mentioned

\footnotetext{
${ }^{2}$ Increased substitutability across energy seems a reasonable benchmark assumption in a model like ours, where we concentrate on long-run effects. For similar reasons, our analysis abstracts from short-run fluctuations in supply and demand for energy, and from the corresponding short-run volatility in energy prices.
} 
above, $f_{t}$ denotes the fossil fuel used in energy production at $t$. Thus, the law of motion for the stock of fossil fuel is: $w_{t+1} \leq w_{t}-f_{t}$. The fossil-fuel-derived energy production function is given by $e_{t}^{f} \leq\left(f_{t}\right)^{1-\alpha_{f}}\left(k_{t}^{f}\right)^{\alpha_{f}}$, where $\alpha_{f} \in(0,1)$. We assume a competitive sector of renewable energy-producing firms. As these firms are heterogenous, we need to keep track of the identity of each individual firm. The renewable energy production function for firm $j$ is given by $e_{j, t}^{r} \leq \Psi\left(i_{j, t}\right)\left(\mathcal{E}_{j, t}\right)^{1-\alpha_{r}}\left(k_{j, t}^{r}\right)^{\alpha_{r}}$, where $\mathcal{E}_{j, t}$ is a productivity parameter, and $\alpha_{r} \in(0,1)$. We interpret $i_{j, t}$ as the innovation expenditure by renewable firm $j$ in period $t$. Innovation is costly, but it can boost productivity in the renewable energy sector. ${ }^{3}$ The innovation cost $i_{j, t}$ is captured by a reduction in firm $j$ 's current output. This is reduced by a factor $\Psi\left(i_{j, t}\right)$, where $\Psi(\cdot)$ is such that $\Psi(0)=1, \Psi^{\prime}(\cdot)<0, \Psi^{\prime \prime}(\cdot)<0$, and $\Psi(i)=0$, for $i=\bar{i}$. In each period, the variables $i_{j, t}$ and $k_{j, t}^{r}$ are chosen after the realization of $\mathcal{E}_{j, t}$. We also assume that there is a spillover effect, as aggregate investment affects the productivity of each individual firm. Put differently, as more firms innovate, the benefits from new ideas affect the entire sector. This creates an externality, implying a discrepancy between equilibrium and desirable levels of investment in renewable energy. Total capital used in the economy cannot exceed the total supply; i.e., $k_{t}^{g}+k_{t}^{f}+\int_{0}^{1} k_{j, t}^{r} d j \leq k_{t}$, all $t$. Finally, we need to specify the mapping between the innovation costs and the resulting productivity improvements. The productivity of each renewable-energy firm depends on its own investment, as well as on the aggregate level of investment by all renewable-energy firms. More precisely, the productivity of firm $j$ evolves deterministically according to:

$$
\ln \mathcal{E}_{j, t+1} \leq \xi i_{j, t}+(1-\xi)\left(\int_{0}^{1} i_{j, t} k_{j, t}^{r} d j / \int_{0}^{1} k_{j, t}^{r} d j\right)+\ln \mathcal{E}_{j, t}
$$

where $0 \leq \xi \leq 1$

We begin by characterizing efficient allocations. These allocations solve the following social planner's problem.

\footnotetext{
${ }^{3}$ Admittedly, a significant amount of innovation occurs in the fossil fuel sector. Mainly for simplicity, in this paper we will concentrate on technological progress in the renewable sector.
} 


$$
\begin{gathered}
\max _{\left\{c_{t}, k_{t+1}, k_{t}^{g}, k_{t}^{f}, w_{t+1}^{f}, f_{t}, e_{t}^{f}, \Gamma_{t}^{p}, \Gamma_{t}^{d},\left\{i_{j, t+1}, k_{j, t}^{r}, \mathcal{E}_{j, t+1}, e_{j, t}^{r}\right\}_{j=0}^{1}\right\}_{t=0}^{\infty}} E \sum_{t=0}^{\infty} \beta^{t} u\left(c_{t}\right) \\
\text { s.t. } c_{t}+k_{t+1} \leq A_{t}\left(k_{t}^{g}\right)^{\theta_{k}}\left(L_{t}\right)^{\theta_{L}}\left(e_{t}\right)^{1-\theta}+(1-\delta) k_{t}: \mu_{R, t} \\
w_{t+1} \leq w_{t}-f_{t}: \mu_{W, t} \\
\Gamma_{t}^{p}=\Gamma_{t-1}^{p}+\varphi_{L} f_{t}: \mu_{\Gamma_{t}^{p}} \\
\Gamma_{t}^{d}=(1-\varphi) \Gamma_{t-1}^{d}+\left(1-\varphi_{L}\right) \varphi_{0} f_{t}: \mu_{\Gamma_{t}^{d}} \\
e_{j, t}^{r} \leq \Psi\left(i_{j, t}\right)\left(\mathcal{E}_{j, t}\right)^{1-\alpha_{r}}\left(k_{j, t}^{r}\right)^{\alpha_{r}}:\left(\mu_{r, t}^{j} d j\right), \\
e_{t}^{f} \leq\left(f_{t}\right)^{1-\alpha_{f}}\left(k_{t}^{f}\right)^{\alpha_{f}}: \mu_{F, t} \\
k_{t} \geq k_{t}^{g}+k_{t}^{f}+\int_{0}^{1} k_{j, t}^{r} d j: \mu_{K, t} \\
\ln \mathcal{E}_{t+1}^{j} \leq \xi i_{j, t}+(1-\xi)\left(\int_{0}^{1} i_{j, t} k_{j, t}^{r} d j / \int_{0}^{1} k_{j, t}^{r} d j\right)+\ln \mathcal{E}_{j, t}:\left(\mu_{\mathcal{E}, t}^{j} d j\right) \\
e_{t} \leq e_{t}^{f}+\int_{0}^{1} e_{j, t}^{r} d j: \mu_{E, t} \\
0 \leq f_{t}: \mu_{f_{t}} \\
k_{t+1} \geq 0, w_{t+1} \geq 0, \text { all } t \\
k_{0}>0, \mathcal{E}_{j, t}>0, w_{0}>0, \text { given }
\end{gathered}
$$

The FOCs, which are also sufficient, for the planner's problem are:

$$
\begin{gathered}
\partial c_{t}: \beta^{t} u^{\prime}\left(c_{t}\right)=\mu_{R, t} \\
\partial k_{t+1}:-\mu_{R, t}+(1-\delta) E_{t} \mu_{R, t+1}+E_{t} \mu_{K, t+1}=0 \\
\partial w_{t+1}: \mu_{W, t}=E_{t} \mu_{W, t+1} \\
\partial \Gamma_{t}^{p}: \mu_{\Gamma_{t}^{p}}-E_{t} \mu_{\Gamma_{t+1}^{p}}-\pi y_{t} \mu_{R, t}=0 \\
\partial \Gamma_{t}^{d}: \mu_{\Gamma_{t}^{d}}-(1-\varphi) E_{t} \mu_{\Gamma_{t+1}^{d}}-\pi y_{t} \mu_{R, t}=0 \\
\partial f_{t}:-\mu_{W, t}+\mu_{F, t}(1-\alpha)\left(\frac{k_{t}^{f}}{f_{t}}\right)^{\alpha_{f}}-\mu_{\Gamma_{t}^{p}} \varphi_{L}-\mu_{\Gamma_{t}^{d}}\left(1-\varphi_{L}\right) \varphi_{0}+\mu_{f_{t}}=0 \\
\partial e_{j t}^{r}: \mu_{r, t}^{j} d j=\mu_{E, t} \text { or } \int \mu_{r, t}^{j} d j=\mu_{E, t}
\end{gathered}
$$


Note that the marginal utility of having a firm producing an extra infinitesimal amount of renewable energy should be equal across firms; i.e., $\mu_{r, t}^{j}=\mu_{r, t}^{l}$, for almost any two firms $j$ and $l$. We then have:

$$
\begin{gathered}
\partial e_{t}^{f}:-\mu_{F, t}+\mu_{E, t}=0 \\
\partial e_{t}: \mu_{R, t}(1-\theta) A_{t} \frac{\left(k_{t}^{g}\right)^{\theta_{k}}\left(L_{t}\right)^{\theta_{L}}}{\left(e_{t}\right)^{\theta}}=\mu_{E, t} \\
\partial k_{t}^{g}: \mu_{R, t} \theta_{k} A_{t}\left(k_{t}^{g}\right)^{\theta_{k}-1}\left(L_{t}\right)^{\theta_{L}}\left(e_{t}\right)^{1-\theta}=\mu_{K, t} \\
\partial k_{t}^{f}: \mu_{F, t} \alpha_{f}\left(\frac{f_{t}}{k_{t}^{f}}\right)^{1-\alpha_{f}}=\mu_{K, t} \\
\partial k_{j, t}^{r}:(1-\xi)\left(\frac{i_{j, t}-\overline{i_{t}}}{\overline{k_{t}^{r}}}\right) \int_{0}^{1} \mu_{\mathcal{E}, t}^{l} d l+\Psi\left(i_{j, t}\right) \alpha_{r} \mu_{r, t}^{j}\left(\frac{\mathcal{E}_{j t}}{k_{j t}^{r}}\right)^{1-\alpha_{r}}=\mu_{K, t}
\end{gathered}
$$

where $\overline{k_{t}^{r}}=\int k_{t, l}^{r} d l$, and $\overline{i_{t}}=\int_{0}^{1} i_{j, t} k_{j, t}^{r} d j / \int_{0}^{1} k_{j, t}^{r} d j$.

Since from (11) $\mu_{r, t}^{j}=\mu_{E, t}$ a.e., (16) implies that $i_{j, t}$ is a function of $\frac{\mathcal{E}_{j t}}{k_{j t}^{r}}$ only. Another first order condition gives

$$
\partial i_{j, t}: \Psi^{\prime}\left(i_{j, t}\right)\left(\mathcal{E}_{j, t}\right)^{1-\alpha_{r}}\left(k_{j, t}^{r}\right)^{\alpha_{r}} \mu_{r, t}^{j} d j+\xi \mu_{\mathcal{E}, t}^{j} d j+(1-\xi) \frac{k_{j, t}^{r}}{\overline{k_{t}^{r}}} d j \int_{0}^{1} \mu_{\mathcal{E}, t}^{l} d l=0
$$

which implies

$$
\partial i_{j, t}:-\mu_{r, t}^{j} \Psi^{\prime}\left(i_{j, t}\right)\left(\frac{\mathcal{E}_{j, t}}{k_{j, t}^{r}}\right)^{1-\alpha_{r}}=\xi \frac{\mu_{\mathcal{E}, t}^{j}}{k_{j, t}^{r}}+(1-\xi) \frac{\int_{0}^{1} \mu_{\mathcal{E}, t}^{l} d l}{\overline{k_{t}^{r}}}
$$

As $\mu_{r, t}^{j}=\mu_{E, t}=\mu_{F, t}$, and $i_{j, t}$ is only a function of $\frac{\mathcal{E}_{j t}}{k_{j t}^{r}}$, we have that $\frac{\mu_{\mathcal{E}, t}^{j}}{k_{j, t}^{r}}$ is also a function of $\frac{\mathcal{E}_{j t}}{k_{j t}^{r}}$. The following Proposition greatly simplifies our analysis. It asserts that if $\mathcal{E}_{j, t}$ and $k_{j, t}^{r}$ are proportional to the initial values of $\mathcal{E}_{j, 0}$, then $i_{j, t}=i_{t}$. Although renewable energyproducing firms are heterogeneous, efficiency implies that they will choose identical levels of investment in R\&D.

Lemma 1. There is an efficient allocation satisfying $\frac{k_{l, t}^{r}}{\mathcal{E}_{l, t}}=\frac{k_{t}^{r}}{\mathcal{E}_{t}}$ and $i_{l, t}=i_{t}$, for all $l$.

Proof. For any initial values of $\mathcal{E}_{j, 0}$, there is a solution such that $\mathcal{E}_{j, t}, k_{j, t}^{r}, \mu_{\mathcal{E}, t}^{j}$ and $\mu_{r, t}^{j}$ are all proportional to the initial values of $\mathcal{E}_{j, 0}$. In this case, (18) implies that $i_{l, t}=i_{t}$, for all $j \in[0,1]$. From (16), $\frac{\mathcal{E}_{j t}}{k_{j t}^{r}}$ is a function of $i_{j, t}$ only. Since $i_{l, t}=i_{t}$, we have $\frac{\mathcal{E}_{j t}}{k_{j t}^{r}}=\frac{\mathcal{E}_{t}}{k_{t}^{r}}$. 


\section{Equilibrium and Policy}

Here we solve for a competitive equilibrium of the above economy and demonstrate that, as argued earlier, there is discrepancy between equilibrium and optimal allocations. We also discuss the role of policy in restoring efficiency.

The household's problem is given by

$$
\begin{gathered}
\max \sum_{t=0}^{\infty} \beta^{t} u\left(c_{t}\right) \\
\text { s.t. } \sum_{t=0}^{\infty} p_{t}\left[c_{t}+k_{t+1}-(1-\delta) k_{t}\right] \leq \sum_{t=0}^{\infty} p_{t}\left[r_{t} k_{t}+w_{L, t} L_{t}+p_{t}^{f} f_{t}+\pi_{t}^{g}+\pi_{t}^{f}+\int_{0}^{1} \pi_{j, t}^{r} d j\right]: \lambda \\
w_{t+1} \leq w_{t}-f_{t}: \mu_{t}
\end{gathered}
$$

where $p_{t}$ is the Arrow-Debreu price of the period- $t$ final good, $r_{t}$ is the rental price of capital in period $t, p_{t}^{f}$ is the price of fossil fuel in period $t$, and $\pi$ stands for the respective firms' profits. The FOC, which are also sufficient for a maximum, can be rewritten as

$$
\begin{gathered}
\frac{p_{t+1}}{p_{t}}=\frac{p_{t}^{f}}{p_{t+1}^{f}} \\
\beta^{t} \frac{u^{\prime}\left(c_{t}\right)}{p_{t}}=\lambda \\
1-\delta+r_{t+1}=\frac{p_{t}}{p_{t+1}} \\
\beta^{t} u^{\prime}\left(c_{t}\right) p_{t}^{f}=\mu_{t}=\mu
\end{gathered}
$$

The final-good firm's problem is

$$
\max \left[A_{t} \cdot\left(k_{t}^{g}\right)^{\theta_{k}}\left(L_{t}\right)^{\theta_{L}}\left(e_{t}\right)^{1-\theta}-r_{t} k_{t}^{g}-w_{L, t} L_{t}-p_{t}^{e} e_{t}\right]
$$

The first order conditions are

$$
\begin{gathered}
\partial k_{t}^{g}: \theta_{k} A_{t}\left(k_{t}^{g}\right)^{\theta_{k}-1}\left(L_{t}\right)^{\theta_{L}}\left(e_{t}\right)^{1-\theta}=r_{t} \\
\partial L_{t}: \theta_{L} A_{t}\left(k_{t}^{g}\right)^{\theta_{k}}\left(L_{t}\right)^{\theta_{L}-1}\left(e_{t}\right)^{1-\theta}=w_{L, t} \\
\partial e_{t}:(1-\theta) A_{t} \frac{\left(k_{t}^{g}\right)^{\theta_{k}}\left(L_{t}\right)^{\theta_{L}}}{e_{t}^{\theta}}=p_{t}^{e}
\end{gathered}
$$

The fossil-fuel Firm's Problem is 


$$
\begin{gathered}
\max \left[p_{t}^{e}\left(f_{t}\right)^{1-\alpha_{f}}\left(k_{t}^{f}\right)^{\alpha_{f}}-r_{t} k_{t}^{f}-p_{t}^{f} f_{t}\right] \\
\partial k_{t}^{f}: p_{t}^{e} \alpha_{f}\left(\frac{f_{t}}{k_{t}^{f}}\right)^{1-\alpha_{f}}=r_{t} \\
\partial f_{t}: p_{t}^{e}\left(1-\alpha_{f}\right)\left(\frac{k_{t}^{f}}{f_{t}}\right)^{\alpha_{f}}=p_{t}^{f}
\end{gathered}
$$

Finally, the renewable firm $j$ 's problem in period $t$ is

$$
\begin{gathered}
\max _{\left\{i_{j, t+\tau}, k_{j, t+\tau}^{r}\right\}_{\tau=0}^{\infty}} \sum_{\tau=0}^{\infty} \beta^{\tau} \frac{u^{\prime}\left(c_{t+\tau}\right)}{u^{\prime}\left(c_{t}\right)}\left[p_{t+\tau}^{e} \Psi\left(i_{j, t+\tau}\right)\left(\mathcal{E}_{j, t+\tau}\right)^{1-\alpha_{r}}\left(k_{j, t+\tau}^{r}\right)^{\alpha_{r}}-r_{t+\tau} k_{j, t+\tau}^{r}\right] \\
\text { s.t. } \ln \mathcal{E}_{t+1}^{j} \leq \ln \mathcal{E}_{t}^{j}+\xi i_{j, t}+(1-\xi)\left(\int_{0}^{1} i_{j, t} k_{j, t}^{r} d j / \int_{0}^{1} k_{j, t}^{r} d j\right): \lambda_{\mathcal{E}, t}^{j} \\
i_{j, t} \geq 0, \text { and } \mathcal{E}_{0} \text { given }
\end{gathered}
$$

Here, $\Psi(\cdot)$ is a convex function, with $\Psi(0)=0, \Psi^{\prime}>0, \Psi^{\prime \prime}>0, \lim _{x \rightarrow 0} \Psi^{\prime}(x)=0$. The FOC are

$$
\begin{gathered}
\partial k_{j, t+\tau}^{r}: p_{t+\tau}^{e} \alpha_{r} \Psi\left(i_{j, t+\tau}\right)\left(\frac{\mathcal{E}_{j, t+\tau}}{k_{j, t+\tau}^{r}}\right)^{1-\alpha_{r}}=r_{t+\tau} \\
\partial i_{j, t+\tau}: \beta^{\tau} \frac{u^{\prime}\left(c_{t+\tau}\right)}{u^{\prime}\left(c_{t}\right)} p_{t+\tau}^{e} \Psi^{\prime}\left(i_{j, t+\tau}\right)\left(\mathcal{E}_{j, t+\tau}\right)^{1-\alpha_{r}}\left(k_{j, t+\tau}^{r}\right)^{\alpha_{r}}=\xi \lambda_{\mathcal{E}, t+\tau}^{j} \\
\partial \mathcal{E}_{t+\tau}^{j}: \lambda_{\mathcal{E}, t+\tau}^{j} \frac{1}{\mathcal{E}_{t+\tau}^{j}}-\lambda_{\mathcal{E}, t+\tau-1}^{j} \frac{1}{\mathcal{E}_{t+\tau}^{j}}+\beta^{\tau} \frac{u^{\prime}\left(c_{t+\tau}\right)}{u^{\prime}\left(c_{t}\right)} p_{t+\tau}^{e}\left(1-\alpha_{r}\right) \Psi\left(i_{j, t+\tau}\right)\left(\frac{k_{j, t+\tau}^{r}}{\mathcal{E}_{j, t+\tau}}\right)^{\alpha_{r}}=0
\end{gathered}
$$

Next, we characterize the equilibrium choice of investment in the renewable technology. We establish that, provided that $\xi<1$, this investment will be lower than optimal. Clearly, this distortion depends on the level of the externality, $\xi$.

Proposition 2. In competitive equilibrium with $\xi<1, i$ is lower than the optimal level.

Proof. From (34) we have

$$
\lambda_{\mathcal{E}, t+\tau-1}^{j}=\lambda_{\mathcal{E}, t+\tau}^{j}-\beta^{\tau} \frac{u^{\prime}\left(c_{t+\tau}\right)}{u^{\prime}\left(c_{t}\right)} p_{t+\tau}^{e}\left(1-\alpha_{r}\right) \Psi\left(i_{j, t+\tau}\right)\left(\mathcal{E}_{t+\tau}^{j}\right)^{1-\alpha_{r}}\left(k_{j, t+\tau}^{r}\right)^{\alpha_{r}}
$$

Condition (33) implies

$$
\frac{\Psi^{\prime}\left(i_{j, t+\tau-1}\right)}{\Psi\left(i_{j, t+\tau-1}\right)} \frac{p_{t+\tau-1}^{e}}{p_{t+\tau}^{e}} e_{j, t+\tau-1}^{r}=\beta \frac{u^{\prime}\left(c_{t+\tau}\right)}{u^{\prime}\left(c_{t+\tau-1}\right)} e_{j, t+\tau}^{r} \frac{\Psi^{\prime}\left(i_{j, t+\tau}\right)}{\Psi\left(i_{j, t+\tau}\right)}\left[1-\xi \frac{\left(1-\alpha_{r}\right)}{\frac{\Psi^{\prime}\left(i_{j, t+\tau}\right)}{\Psi\left(i_{j, t+\tau}\right)}}\right]
$$


For $\tau=1$, the optimality condition is

$$
\frac{p_{t}^{e}}{p_{t+1}^{e}} \frac{e_{t}^{r}}{e_{t+1}^{r}} \frac{u^{\prime}\left(c_{t}\right) \Psi^{\prime}\left(i_{t}\right) / \Psi\left(i_{t}\right)}{\beta u^{\prime}\left(c_{t+1}\right) \Psi^{\prime}\left(i_{t+1}\right) / \Psi\left(i_{t+1}\right)}=\left(1-\xi \frac{1-\alpha_{r}}{\Psi^{\prime}\left(i_{t+1}\right) / \Psi\left(i_{t+1}\right)}\right)
$$

Replacing $\alpha_{r} p_{t}^{e} e_{t}^{r}=r_{t} k_{j, t}^{r}$ in the equation above, we obtain

$$
r_{t} k_{j, t}^{r} \Psi^{\prime}\left(i_{t}\right) / \Psi\left(i_{t}\right)=r_{t+1} k_{j, t+1}^{r} \beta \frac{u^{\prime}\left(c_{t+1}\right)}{u^{\prime}\left(c_{t}\right)} \Psi^{\prime}\left(i_{t+1}\right) / \Psi\left(i_{t+1}\right)-\xi\left(1-\alpha_{r}\right) r_{t+1} k_{j, t+1}^{r} \beta \frac{u^{\prime}\left(c_{t+1}\right)}{u^{\prime}\left(c_{t}\right)}
$$

or,

$$
\begin{aligned}
& u^{\prime}\left(c_{t}\right) r_{t} k_{j, t}^{r} \Psi^{\prime}\left(i_{t}\right) / \Psi\left(i_{t}\right) \\
= & \lim _{\tau \rightarrow \infty} \beta^{\tau} r_{t+\tau} k_{j, t+\tau}^{r} u^{\prime}\left(c_{t+\tau}\right) \Psi^{\prime}\left(i_{t+\tau}\right) / \Psi\left(i_{t+\tau}\right) \\
& -\xi \sum_{\tau=1}^{\infty} \beta^{\tau} u^{\prime}\left(c_{t+\tau}\right)\left(1-\alpha_{r}\right) r_{t+1} k_{j, t+1}^{r}
\end{aligned}
$$

Comparing the above expression with the corresponding one for the optimal $i$ establishes that in a competitive equilibrium without policy intervention the efficient allocation is not achievable.

Next, we discuss implementation and optimal policy. This needs to take into account two distortions. The first, relates to under-investment in $i$ due to the spillover effects. The second involves the social costs associated with the environmental externality. The next Proposition demonstrates that these two distortions can be fully accommodated through the use of two policy instruments. First, a policy that taxes firms in proportion to their under-investment in $i$ restores optimal investment by making firms indifferent when they choose between paying the tax or pursuing the optimal level of investment. As in GHKT (2012), under the special assumptions of log utility and $100 \%$ depreciation of capital, the tax of fossil fuel firms does not depend on the growth rate of the economy.

Proposition 3. (1) The optimal allocation can be supported by a combination of a revenueneutral policy $\Phi_{t}^{j}\left(i_{j, t}\right)=-(1-\xi) p_{t}^{e} \Psi^{\prime}\left(i_{j, t}^{*}\right)\left(\frac{e_{j, t}^{* r}}{\Psi\left(i_{j, t}^{*}\right)}\right)\left(i_{j, t}-i_{t}^{*}\right)$ imposed on renewable firms, together with a Pigouvian tax on the usage of fossil fuel: $\tau_{t}^{f}=\sum_{j=0}^{\infty} \beta^{j} \frac{u^{\prime}\left(c_{t+j}^{*}\right)}{u^{\prime}\left(c_{t}^{*}\right)} \pi_{t+j} y_{t+j}^{*}\left(1-d_{j}\right)$, where $\left\{c_{t}^{*}, y_{t}^{*}\right\}_{t=0}^{\infty}$ is the solution to the planner's problem, and $1-d_{j}=\varphi_{L}+\left(1-\varphi_{L}\right) \varphi_{0}(1-\varphi)^{j}$; (2) The Pigouvian tax on the usage of fossil fuel, $\tau_{t}^{f}$, does not depend on the growth rate of the economy if $u(c)=\log (c), \alpha_{r}=\alpha_{f}=\alpha$, and $\delta=1$.

Proof. (1) Renewable-energy-producing firm $j$ 's problem can be written as

$$
\begin{aligned}
\max _{\left\{i_{j, t}\right\}_{t=0}^{\infty}} \sum_{\tau=0}^{\infty} \beta^{\tau} \frac{u^{\prime}\left(c_{t+\tau}\right)}{u^{\prime}\left(c_{t}\right)}\left[p_{t+\tau}^{e} \Psi\left(i_{j, t+\tau}\right)\left(\mathcal{E}_{j, t+\tau}\right)^{1-\alpha_{r}}\left(k_{j, t}^{r}\right)^{\alpha_{r}}-r_{t+\tau} k_{j, t}^{r}+\Phi_{t+\tau}^{j}\right] \\
\text { s.t. } \ln \mathcal{E}_{t+1}^{j} \leq \ln \mathcal{E}_{t}^{j}+\xi i_{j, t}+(1-\xi)\left(\int_{0}^{1} i_{j, t} k_{j, t}^{r} d j / \int_{0}^{1} k_{j, t}^{r} d j\right): \lambda_{\mathcal{E}, t}^{j} \\
i_{j, t} \geq 0 \text {, and } \mathcal{E}_{0} \text { given }
\end{aligned}
$$


The FOC are

$$
\begin{gathered}
\partial k_{j, t+\tau}^{r}: p_{t+\tau}^{e} \alpha_{r} \Psi\left(i_{j, t+\tau}\right)\left(\frac{\mathcal{E}_{j, t+\tau}}{k_{j, t+\tau}^{r}}\right)^{1-\alpha_{r}}=r_{t+\tau} \\
\partial i_{j, t+\tau}: \beta^{\tau} \frac{u^{\prime}\left(c_{t+\tau}\right)}{u^{\prime}\left(c_{t}\right)} p_{t+\tau}^{e} \Psi^{\prime}\left(i_{j, t+\tau}\right)\left(\frac{e_{j, t+\tau}^{r}}{\Psi\left(i_{j, t+\tau}\right)}\right)-(1-\xi) \beta^{\tau} \frac{u^{\prime}\left(c_{t+\tau}\right)}{u^{\prime}\left(c_{t}\right)} p_{t+\tau}^{e} \Psi^{\prime}\left(i_{j, t+\tau}^{*}\right)\left(\frac{e_{j, t+\tau}^{* r}}{\Psi\left(i_{j, t+\tau}^{*}\right)}\right)=\xi \lambda_{\mathcal{E}, t+\tau}^{j} \\
\partial \mathcal{E}_{t+\tau}^{j}: \lambda_{\mathcal{E}, t+\tau}^{j} \frac{1}{\mathcal{E}_{t+\tau}^{j}}-\lambda_{\mathcal{E}, t+\tau-1}^{j} \frac{1}{\mathcal{E}_{t+\tau}^{j}}+\beta^{\tau} \frac{u^{\prime}\left(c_{t+\tau}\right)}{u^{\prime}\left(c_{t}\right)} p_{t+\tau}^{e}\left(1-\alpha_{r}\right)\left(\frac{k_{j, t+\tau}^{r}}{\mathcal{E}_{j, t+\tau}}\right)^{\alpha_{r}}=0
\end{gathered}
$$

Using (36), at the optimum we have

$$
\lambda_{\mathcal{E}, t+\tau}^{j}=\beta^{\tau} \frac{u^{\prime}\left(c_{t+\tau}\right)}{u^{\prime}\left(c_{t}\right)} p_{t+\tau}^{e} \Psi^{\prime}\left(i_{j, t+\tau}^{*}\right)\left(\frac{e_{j, t+\tau}^{* r}}{\Psi\left(i_{j, t+\tau}^{*}\right)}\right)
$$

Substituting the above in (35), we obtain an identical expression to that for the optimal $i$.

Next, suppose sellers of fossil fuel face a linear tax rate

$$
\tau_{t}^{f}=\sum_{j=0}^{\infty} \beta^{j} \frac{u^{\prime}\left(c_{t+j}^{*}\right)}{u^{\prime}\left(c_{t}^{*}\right)} \pi_{t+j} y_{t+j}^{*}\left(1-d_{j}\right)
$$

where $\left\{c_{t}^{*}, y_{t}^{*}\right\}_{t=0}^{\infty}$ solve the planner's problem, and $1-d_{j}=\varphi_{L}+\left(1-\varphi_{L}\right) \varphi_{0}(1-\varphi)^{j}$. Under this tax, the fossil-fuel-producers' optimal intertemporal substitution implies

$$
u^{\prime}\left(c_{t}\right)\left\{p_{t}^{f}-\tau_{t}^{f}\right\}=\beta u^{\prime}\left(c_{t+1}\right)\left\{p_{t+1}^{f}-\tau_{t+1}^{f}\right\}
$$

Using (27) and (30) for the price of fossil fuel and (37) for the tax, we obtain

$$
\begin{aligned}
& u^{\prime}\left(c_{t}\right)\left\{M P F_{t}-\pi_{t} y_{t}^{*}\left(\varphi_{L}+\left(1-\varphi_{L}\right) \varphi_{0}\right)\right\} \\
& +\sum_{j=1}^{\infty} \beta^{j} u^{\prime}\left(c_{t+j}^{*}\right) \pi_{t+j} y_{t+j}^{*}\left(\left(1-\varphi_{L}\right) \varphi_{0}(1-\varphi)^{j-1} \varphi\right) \\
= & \beta u^{\prime}\left(c_{t+1}\right)\left\{M P F_{t+1}\right\}
\end{aligned}
$$

Clearly, if $\frac{y_{t+j}^{*}}{c_{t+1}^{*}}=\chi$, a constant, the claim would be true. First, observe that $\frac{c_{t}}{y_{t}}=\chi \Leftrightarrow \frac{k_{t+1}^{g}}{y_{t}}=$ $\theta^{k} \beta$. This follows from the first order conditions of the social planner which include

$$
\frac{y_{t}}{c_{t}}=\frac{y_{t+1}}{c_{t+1}} \frac{\theta^{k} \beta y_{t}}{k_{t+1}^{g}}
$$

It remains to show that

$$
\frac{k_{t+1}^{f}}{y_{t}}+\frac{k_{t+1}^{r}}{y_{t}}=1-\chi-\theta^{k} \beta \equiv \varrho
$$


where $k_{t}^{r}=\int k_{t, l}^{r} d l$. The social planner's problem FOC with respect to $k_{j, t}^{r}$ implies

$$
\begin{gathered}
\alpha_{r} \Psi\left(i_{t}\right)\left(\frac{\mathcal{E}_{j, t}}{k_{j, t}^{r}}\right)^{1-\alpha_{r}}(1-\theta) \frac{y_{t}}{e_{t}}=\alpha_{r}\left(\frac{e_{j, t}^{r}}{k_{j, t}^{r}}\right)(1-\theta) \frac{y_{t}}{e_{t}}=\theta^{k} \frac{y_{t}}{k_{t}^{g}} \\
\alpha_{r}(1-\theta) \frac{e_{j, t}^{r}}{e_{t}}=\frac{1}{\beta} \frac{k_{j, t}^{r}}{y_{t-1}}
\end{gathered}
$$

The social planner FOC with respect to $k_{t}^{f}$ implies

$$
\alpha_{f}(1-\theta) \frac{e_{t}^{f}}{e_{t}}=\frac{1}{\beta} \frac{k_{t}^{f}}{y_{t-1}}
$$

It is sufficient to show that

$$
\beta(1-\theta)\left(\frac{\alpha_{r} e_{t+1}^{r}+\alpha_{f} e_{t+1}^{f}}{e_{t+1}}\right)=\varrho
$$

which is true if $\alpha_{r}=\alpha_{f}=\alpha$.

The implied policy has some interesting implications. The tax on renewable energy firms generates no revenue, but it reduces households' profits from the renewable sector, as a result of inducing additional innovation. The Pigouvian tax reduces households' profits from the fossil fuel sector. However, households receive a lump-sum transfer of equal magnitude, thus, their budget constraint remains unchanged. Finally, there is no interaction between these two schemes, since the total effect on households' budget is the same as the resource cost of innovation in the planner's problem.

For the remainder of the Section we will keep the assumption that $u(c)=\log (c)$ and $\delta=1$. Moreover, we assume that the stock of fossil fuel is large enough so that consumption of fossil fuel is never constrained. However, as we will show, the total consumption of fossil fuel is bounded.

Let $V\left(k ; A, L, \mathcal{E} ; \Gamma^{p}, \Gamma^{d}\right)$ denote the value of $k$ units of capital when the aggregate productivity is $A$, the labor supply is $L$, the productivity in the renewable energy sector is $\mathcal{E}$, and the stocks of permanent and depreciating emissions are $\Gamma^{p}$ and $\Gamma^{d}$, respectively. The optimal consumption and saving decision under log utility and full depreciation is given by $c=(1-\beta \Theta) y$, and $k^{\prime}=\beta \Theta y$, where $\Theta=\theta_{k}+\left(1-\theta_{k}-\theta_{\ell}\right) \alpha$ is the marginal product of capital. The recursive formulation for $V(\cdot)$ is given by

$$
\begin{aligned}
V\left(k ; A, L, \mathcal{E} ; \Gamma^{p}, \Gamma^{d}\right)= & \max _{i, f} \ln ((1-\beta \Theta) y) \\
& +\beta V\left(\beta \Theta y ; g^{g} A, g^{L} L, e^{i} \mathcal{E} ; \Gamma^{p}+\varphi_{L} f,(1-\varphi) \Gamma^{d}+\left(1-\varphi_{L}\right) \varphi_{0} f\right) \\
& \text { where } \\
& y=e^{-\pi\left(\bar{\Gamma}-\Gamma^{p}-\Gamma^{d}\right)} A L^{\theta_{\ell}}\left(f+\Psi(i)^{\frac{1}{1-\alpha}} \mathcal{E}\right)^{(1-\alpha)\left(1-\theta_{k}-\theta_{\ell}\right)} k^{\Theta}
\end{aligned}
$$


Utilizing the properties of the log function and the envelope theorem, we have $V_{k}=\Theta \frac{1}{k}+$ $\beta \Theta \frac{k^{\prime}}{k} V_{k^{\prime}}^{\prime}$, which implies

$$
k V_{k}=\Theta+\beta \Theta k^{\prime} V_{k^{\prime}}
$$

Next, we guess that $k V_{k}$ is a constant and we verify that

$$
V_{k}=\frac{\Theta}{1-\beta \Theta} \frac{1}{k}
$$

Using the same method, we have that $V_{A}=\frac{1}{A}+\beta\left\{\frac{k^{\prime}}{A} V_{k^{\prime}}^{\prime}+g^{g} V_{A^{\prime}}^{\prime}\right\}$, which, in turn, implies

$$
A V_{A}=1+\beta\left\{\frac{\Theta}{1-\beta \Theta}+\left(g^{g} A\right) V_{A^{\prime}}^{\prime}\right\}
$$

If we guess that $A V_{A}$ is a constant, noting that $A^{\prime}=g^{g} A$, we can verify that

$$
V_{A}=\frac{1}{(1-\beta)(1-\beta \Theta)} \frac{1}{A}
$$

Similarly, we obtain

$$
\begin{aligned}
V_{L} & =\frac{\theta_{L}}{(1-\beta)(1-\beta \Theta)} \frac{1}{L} \\
V_{\Gamma^{p}} & =\frac{1}{(1-\beta)(1-\beta \Theta)}(-\pi) \\
V_{\Gamma^{d}} & =\frac{1}{(1-\beta(1-\varphi))(1-\beta \Theta)}(-\pi)
\end{aligned}
$$

where the last expression reflects the depreciation rate of the temporary part of the stock of emissions.

The optimal choice of $f$ implies that

$$
\begin{aligned}
0 & \leq \frac{(1-\alpha)\left(1-\theta_{k}-\theta_{\ell}\right)}{\left(f+\Psi(i)^{\frac{1}{1-\alpha}} \mathcal{E}\right)}+\beta\left\{\frac{(1-\alpha)\left(1-\theta_{k}-\theta_{\ell}\right) k^{\prime}}{\left(f+\Psi(i)^{\frac{1}{1-\alpha}} \mathcal{E}\right)} V_{k^{\prime}}^{\prime}+\varphi_{L} V_{\Gamma^{p^{\prime}}}^{\prime}+\left(\left(1-\varphi_{L}\right) \varphi_{0}\right) V_{\Gamma^{d \prime}}^{\prime}\right\} \\
& \left.=\frac{(1-\alpha)\left(1-\theta_{k}-\theta_{\ell}\right)}{\left(f+\Psi(i)^{\frac{1}{1-\alpha}} \mathcal{E}\right)(1-\beta \Theta)}-\beta\left\{\varphi_{L} \frac{\pi}{(1-\beta)(1-\beta \Theta)}+\left(\left(1-\varphi_{L}\right) \varphi_{0}\right) \frac{\pi}{(1-\beta(1-\varphi))(1-\beta \Theta)}\right)^{46}\right\}
\end{aligned}
$$

which implies that

$$
f+\Psi(i)^{\frac{1}{1-\alpha}} \mathcal{E} \leq \frac{(1-\alpha)\left(1-\theta_{k}-\theta_{\ell}\right)}{\beta\left\{\frac{\pi \varphi_{L}}{(1-\beta)}+\frac{\pi\left(1-\varphi_{L}\right) \varphi_{0}}{(1-\beta(1-\varphi))}\right\}}
$$

with equality for $f>0$. 
The optimal choice for $i$ implies

$$
0=(1-\alpha)\left(1-\theta_{k}-\theta_{\ell}\right) \frac{\frac{1}{1-\alpha} \Psi^{\prime}(i) \Psi(i)^{\frac{1}{1-\alpha}-1} \mathcal{E}}{f+\Psi(i)^{\frac{1}{1-\alpha} \mathcal{E}}}\left\{1+\beta \frac{\Theta}{1-\beta \Theta}\right\}+\beta \underbrace{e^{i} \mathcal{E}}_{\mathcal{E}^{\prime}} V_{\mathcal{E}^{\prime}}^{\prime}
$$

or,

$$
\frac{-\Psi^{\prime}(i)}{\Psi(i)} \frac{\left(1-\theta_{k}-\theta_{\ell}\right)}{1-\beta \Theta} \frac{\Psi(i)^{\frac{1}{1-\alpha}} \mathcal{E}}{f+\Psi(i)^{\frac{1}{1-\alpha}} \mathcal{E}}=\beta \mathcal{E}^{\prime} V_{\mathcal{E}^{\prime}}^{\prime}
$$

where

$$
\mathcal{E} V_{\mathcal{E}}=\frac{(1-\alpha)\left(1-\theta_{k}-\theta_{\ell}\right)}{1-\beta \Theta} \frac{\Psi(i)^{\frac{1}{1-\alpha}} \mathcal{E}}{f+\Psi(i)^{\frac{1}{1-\alpha}} \mathcal{E}}+\beta \mathcal{E}^{\prime} V_{\mathcal{E}^{\prime}}^{\prime}
$$

Combining, we obtain

$$
\frac{-\Psi^{\prime}(i)}{\Psi(i)}=\beta \frac{\frac{\Psi\left(i^{\prime}\right) \frac{1}{1-\alpha} \mathcal{E}^{\prime}}{f^{\prime}+\Psi\left(i^{\prime}\right)^{\frac{1}{1-\alpha}} \mathcal{E}^{\prime}}}{\frac{\Psi(i)^{\frac{1}{1-\alpha} \mathcal{E}}}{f+\Psi(i)^{1-\alpha} \mathcal{L}}}\left((1-\alpha)+\frac{-\Psi^{\prime}\left(i^{\prime}\right)}{\Psi\left(i^{\prime}\right)}\right)
$$

If $f=f^{\prime}=0$, we have $\frac{-\Psi^{\prime}(i)}{\Psi(i)}=\beta\left((1-\alpha)+\frac{-\Psi^{\prime}\left(i^{\prime}\right)}{\Psi\left(i^{\prime}\right)}\right)$, which implies $i=i^{\prime}=i^{s s}$, where $i^{s s}$ is determined by

$$
\frac{-\Psi^{\prime}\left(i^{s s}\right)}{\Psi\left(i^{s s}\right)}=\frac{\beta}{1-\beta}(1-\alpha)
$$

If $f>f^{\prime}=0$, then

$$
\begin{aligned}
\frac{-\Psi^{\prime}(i)}{\Psi(i)} & =\beta \frac{f+\Psi(i)^{\frac{1}{1-\alpha}} \mathcal{E}}{\Psi(i)^{\frac{1}{1-\alpha}} \mathcal{E}}\left((1-\alpha)+\frac{-\Psi^{\prime}\left(i^{\prime}\right)}{\Psi\left(i^{\prime}\right)}\right) \\
& =\beta \frac{f+\Psi(i)^{\frac{1}{1-\alpha}} \mathcal{E}}{\Psi(i)^{\frac{1}{1-\alpha}} \mathcal{E}} \frac{1-\alpha}{1-\beta} \\
& =\frac{(1-\alpha)^{2}}{1-\beta} \frac{\left(1-\theta_{k}-\theta_{\ell}\right)}{\left\{\frac{\pi \varphi_{L}}{(1-\beta)}+\frac{\pi\left(1-\varphi_{L}\right) \varphi_{0}}{(1-\beta(1-\varphi))}\right\}} \frac{1}{\Psi(i)^{\frac{1}{1-\alpha}} \mathcal{E}}
\end{aligned}
$$

If $f, f^{\prime}>0$, then

$$
\begin{aligned}
f^{\prime}+\Psi\left(i^{\prime}\right)^{\frac{1}{1-\alpha}} \mathcal{E}^{\prime} & =f+\Psi(i)^{\frac{1}{1-\alpha}} \mathcal{E} \\
& =\frac{(1-\alpha)\left(1-\theta_{k}-\theta_{\ell}\right)}{\beta\left\{\frac{\pi \varphi_{L}}{(1-\beta)}+\frac{\pi\left(1-\varphi_{L}\right) \varphi_{0}}{(1-\beta(1-\varphi))}\right\}}
\end{aligned}
$$

which implies

$$
\frac{-\Psi^{\prime}(i)}{\Psi(i)}=\beta \frac{\Psi\left(i^{\prime}\right)^{\frac{1}{1-\alpha}} e^{i}}{\Psi(i)^{\frac{1}{1-\alpha}}}\left((1-\alpha)+\frac{-\Psi^{\prime}\left(i^{\prime}\right)}{\Psi\left(i^{\prime}\right)}\right)
$$


Finally, if $f=0$, we have

$$
V_{\mathcal{E}}=\frac{(1-\alpha)\left(1-\theta_{k}-\theta_{\ell}\right)}{(1-\beta)(1-\beta \Theta)} \frac{1}{\mathcal{E}}
$$

Hence,

$$
\begin{aligned}
V\left(k ; A, L, \mathcal{E} ; \Gamma^{p}, \Gamma^{d}\right)= & C+\frac{\Theta}{1-\beta \Theta} \ln k \\
& +\frac{1}{(1-\beta)(1-\beta \Theta)}\left\{\ln A+\theta_{L} \ln L+(1-\alpha)\left(1-\theta_{k}-\theta_{\ell}\right) \ln \mathcal{E}\right\} \\
& -\frac{\pi}{(1-\beta)(1-\beta \Theta)} \Gamma^{p}+\frac{\pi}{(1-(1-\varphi) \beta)(1-\beta \Theta)} \Gamma^{d}
\end{aligned}
$$

where $C$ is a constant.

To determine the path of $i$ and $f$, we start by determining $i^{s s}$. Then the minimum $\mathcal{E}$ for which $f=0$ is determined by

$$
\Psi\left(i^{s s}\right)^{\frac{1}{1-\alpha}} \underline{\mathcal{E}}=\frac{(1-\alpha)\left(1-\theta_{k}-\theta_{\ell}\right)}{\beta\left\{\frac{\pi \varphi_{L}}{(1-\beta)}+\frac{\pi\left(1-\varphi_{L}\right) \varphi_{0}}{(1-\beta(1-\varphi))}\right\}}
$$

For $\mathcal{E}^{\prime} \in\left[\underline{\mathcal{E}}, e^{i s s} \underline{\mathcal{E}}\right)$, the previous period's consumption of fossil fuel is positive, that is, $f>0$, while the current period's fossil fuel is zero. Hence, using (53) and $e^{i} \mathcal{E}=\mathcal{E}^{\prime}$, we have

$$
\frac{-\Psi^{\prime}(i)}{\Psi(i)} \Psi(i)^{\frac{1}{1-\alpha}} \underbrace{e^{-i} \mathcal{E}^{\prime}}_{\mathcal{E}}=\frac{(1-\alpha)^{2}}{1-\beta} \frac{\left(1-\theta_{k}-\theta_{\ell}\right)}{\left\{\frac{\pi \varphi_{L}}{(1-\beta)}+\frac{\pi\left(1-\varphi_{L}\right) \varphi_{0}}{(1-\beta(1-\varphi))}\right\}}
$$

Denote the $i$ and the $\mathcal{E}$ corresponding to $\mathcal{E}^{\prime}=\underline{\mathcal{E}}$ by $\underset{=}{i}$ and $\underline{\mathcal{E}}$, respectively. For $\mathcal{E}^{\prime} \in[\underline{\underline{\mathcal{E}}}, \underline{\mathcal{E}}]$, and using the corresponding $i^{\prime}$, we can compute the previous period's $i$ using (54) and proceed backward. In that case, $i$ converges to $i^{s f}$ determined by

$$
\frac{-\Psi^{\prime}\left(i^{s f}\right)}{\Psi\left(i^{s f}\right)}=\frac{\beta i^{s f}}{1-\beta i^{s f}}(1-\alpha)
$$

Finally given $i$ and $\mathcal{E}$, we can compute the optimal $f$.

\section{Calibration}

Our calibration relies on the derivation from the previous section. The right-hand-side of expression (47) gives the upper bound for the consumption of fossil fuel, assuming that the initial reserves are large enough so that, on the optimal path, the economy stops using fossil fuel before exhausting it. The interpretation is straightforward; we equate the marginal benefit from using fossil fuel to the present value of the future damages. The calibrated values are based on GHKT and imply that this upper bound is $105.78 \mathrm{GtC}$. 
For our numerical experiments, we assume $\Psi(i)=\left(1-\left(\frac{i}{i}\right)^{\psi}\right)^{1 / \psi}$. This leaves us with two parameters to calibrate: $\bar{i}$ and $\psi$. To calibrate $\bar{i}$, we use the fact that expression (58) characterizes the "backward-asymptotic" value of $i$ when fossil fuel is used. This implies $\beta e^{i_{f}}<1$. If $\beta e^{\bar{i}}>1$, then the growth would be unbounded. This is because one can set $i=\bar{i}$ and grow $\mathcal{E}$ (hence output), at a rate faster than discounting. We, thus, set $\bar{i}=\log (\beta)-0.1=0.3082$. That is, the productivity of the renewable energy sector can improve at most by $3.13 \%$ annually, which is broadly consistent with historical cost-reduction averages in the sector.

Given $\bar{i}$, we can calibrate $\psi$. In order to have a balanced growth path, the long-term $i$ should be equal to the long term growth rate. The long term $i$ is, in turn, characterized by (52) and, given $\bar{i}$, we can use this to back up $\psi$.

The Matlab code, simulates the optimal $i, \mathcal{E}$, and fossil fuel production going backward. Moreover, we can calculate the share of renewable energy from the total energy production.

If we assume the current share of renewables to be below $5 \%$, then it should take around 150 years (15 periods) to end the use of fossil fuel. The cumulative consumption of fossil fuel would be around 900GtC. Based on expression (25) in GHKT, this implies a 2.5 degree Celsius temperature increase.

As a robustness check, we have also set $\bar{i}=\log (\beta)-0.01$. In that case, it takes 11 periods (110 years) to go from a $5 \%$ share of renewable production to a $100 \%$ representation of renewables in total energy production. In that case, the cumulative consumption of fossil fuel would be around $1000 \mathrm{GtC}$, which, using the same formula, would imply a 2.67 degree Celsius rise in global temperatures.

\section{Conclusions}

We studied the adaptation of new technologies by renewable energy-producing firms in a dynamic general equilibrium model where energy is an input in the production of final goods. We assumed that the cost of investing in improving the renewable technology is losing some current production of renewable energy. Efficiency requires a policy which promotes adaptation of new technologies by subsidizing investment in renewables. Our quantitative results suggest that investment in renewables has significant long-term positive effects on the composition of energy use, the allocation of capital in the economy, and overall economic growth. 


\section{References}

[1] Acemoglu, D., P. Aghion, L. Bursztyn, and D. Hemous (2012): "The Environment and Directed Technical Change," American Economic Review 102(1) p. 131-166

[2] Acemoglu, D., U. Akcigit, D. Hanley, and W. Kerr (2012): "The Transition to Clean Technology," presentation slides

[3] Arrow K.J. (1962): "Economic Welfare and the Allocation of Resources for Invention," in R. Nelson, eds, The Rate and Direction of Inventive Activity. Princeton University Press

[4] Arrow K.J. (1962): "The economic Implications of Learning by Doing," Review of Economic Studies 29

[5] Bentham, A. van, K. Gillingham, and J. Sweeney (2008): "Learning-by-doing and the optimal solar policy in California," The Energy Journal 29(3) p. 131-152

[6] Cason T.N., and C.R. Plott (1994): "EPA's New Emissions Trading Mechanism: A Laboratory Evaluation," Journal of Environmental Economics and management 30

[7] Chari V.V. and Hugo A. Hopenhayn (1991): "Vintage Human Capital, Growth and the Diffusion of New Technologies," Journal of Political Economy

[8] Chakravorty U., Roumasset J., and K. Tse (1997): "Endogenous Substitution among Energy Resources and Global Warming," Journal of Political Economy 105(6)

[9] Golosov M., J. Hassler, P. Krusell, and A. Tsyvinski (2011): "Optimal Taxes on Fossil Fuel in General Equilibrium," Manuscript

[10] GrÂžbler A. and S. Messner (1998): "Technological change and the timing of mitigation measures", Energy Economics 20, p. 495-512 
[11] Hartley P. and K. Medlock III (2005): "Carbon Dioxide: A Limit to Growth?" Manuscript

[12] Hartley P., Medlock III K, Temzelides T, and X. Zhang (2012): "Energy Sector Innovation and Growth" Manuscript

[13] Hasslr J., P. Krusell, and C. Olovsson (2011): "Energy Saving Technical Change," mimeo, Institute of International Economic Studies, Stockholm University

[14] Hopenhayn, H. (1992): "Entry, Exit, and firm Dynamics in Long Run Equilibrium," Econometrica 60, No. 5

[15] Jovanovic, B. and S. Lach (1989): "Entry, Exit, and Diffusion with Learning by Doing," American Economic Review 79, No. 4

[16] Klaassen, G., A. Miketa, K. Larsen and T. Sundqvist (2005): "The impact of R\&D on innovation for wind energy in Denmark, Germany and the United Kingdom," Ecological Economics, 54

[17] Klette T.J. and S. Kortum (2004): "Innovating Firms and Aggregate Innovation," Journal of Political Economy 112 (5)

[18] Manuelli R. and A. Seshadri (2014): "Frictionless Technology Diffusion: The Case of Tractors," American Economic Review 104(4), 1368-91

[19] Parente, Stephen L. (1994): “Technology Adoption, Learning-by-Doing and Economic Growth," Journal of Economic Theory, 63(2), 346-369

[20] Nordhaus, William and Joseph Boyer (2000): "Warming the World: Economic Modeling of Global Warming," MIT Press, Cambridge, MA

[21] Solow R.M. and F.Y. Wan (1976): "Extraction Costs in the Theory of Exhaustible Resources," Bell Journal of Economics, The RAND Corporation, vol. 7(2), p. 359-370 
[22] Stern N. (2007): The Economics of Climate Change: The Stern Review, Cambridge University Press

[23] Van der Ploeg F., and C. Withagen (2011): "Is There Really a Green Paradox?," OxCarre Research Paper 35 